\title{
Within-stimulus competition in trace conditioning of the rabbit's nictitating membrane response
}

\author{
E. JAMES KEHOE and GABRIELLE WEIDEMANN \\ University of New South Wales, Sydney, New South Wales, Australia
}

\begin{abstract}
In four experiments, it was shown that the onset and offset of a tone conditioned stimulus (CS) in trace conditioning interact in much the same way as a sequence of two stimuli from different sensory sources, such as a tone and a light. The duration of the tone was manipulated across values ranging from 400 to $30,000 \mathrm{msec}$, whereas the trace interval between the tone offset and the US was fixed at $400 \mathrm{msec}$. The rate and level of total CR acquisition were high and constant across all tone durations. Likewise, responding during the trace interval on paired trials was relatively constant. However, when the tone onset and tone offset were tested in relative isolation from each other on test trials using a 30,000 -msec tone, there was a reciprocal relationship in responding to tone onset and tone offset. When training had been conducted with shorter tone durations, responding to tone onset was only moderate but, nonetheless, higher than responding to tone offset, which was negligible. At the longer tone durations, responding to tone onset declined to lower levels, whereas responding to tone offset rose to a high level equal to the total level of responding. These effects were consistent across manipulations of tone intensity and prior delay conditioning, in which only tone onset could function as a CS. Consequently, the trace CS appears to act as a compound stimulus that engages complex associative processes as well as simple associative processes. The implications of the present results for understanding the susceptibility of trace conditioning to hippocampal damage in the rabbit nictitating membrane preparation are discussed.
\end{abstract}

In the present experiments, the acquisition of the rabbit's nictitating membrane (NM) response in trace conditioning, in which the offset of the conditioned stimulus (CS) occurs before the onset of the unconditioned stimulus (US), was examined. In these experiments, we attempted to ascertain whether the offset of a trace CS competes with its onset for command of the conditioned response (CR). The basic empirical question concerned whether the contiguity of the CS offset to the US would be overridden by the temporal primacy of CS onset as a predictor of the US. At a more theoretical level, the primary question concerned whether a trace $\mathrm{CS}$, which might seem to be a singular event, is actually processed as a compound of two distinct stimuli in the same way as compounds of two events from different sensory sources, such as a tone and a light.

These experiments were driven by two issues in the literature involving trace conditioning and its neural substrates. First, there is the relationship between trace conditioning and delay conditioning, in which the CS fills the entire interval between CS onset and US onset. On an operational level, the two procedures appear to differ only quantitatively, but there is evidence that trace condition-

Preparation of this manuscript was supported by Australian Research Council Grant A79600502. The authors thank Anastasia Georgilas and Claudia Mendias-Canale for their assistance in data collection and data analysis. Correspondence should be sent to E. J. Kehoe, School of Psychology, University of New South Wales, Sydney, NSW 2052, Australia (e-mail: j.kehoe@unsw.edu.au). ing depends on more neural apparatus than does delay conditioning. For the rabbit NM preparation, the essential pathways for acquisition and expression of a CR in delay conditioning run largely through the brainstem and cerebellum (Anderson \& Steinmetz, 1994; Thompson \& Krupa, 1994). Trace conditioning requires the same pathways but also relies heavily on the hippocampus and other forebrain structures (Kronforst-Collins \& Disterfhoft, 1997; Ryou \& Kim, 1997). Hippocampectomy hinders CR acquisition and disrupts CR timing in trace conditioning (Moyer, Deyo, \& Disterhoft, 1990; Port, Romano, Steinmetz, Mikhail, \& Patterson, 1986; Solomon, Vander Schaaf, Weisz, \& Thompson, 1986; but see G. O. James, Hardiman, \& Yeo, 1987). In the case of delay conditioning, hippocampectomy has variable effects, sometimes having no effect (Solomon \& Moore, 1975; Solomon et al., 1986) and sometimes enhancing CR acquisition and expression (Orr \& Berger, 1985; Port, Mikhail, \& Patterson, 1985; Schmaltz \& Theios, 1972).

The second issue concerns the role that the hippocampus plays in trace conditioning. Trace conditioning does not readily fit into any of the functions commonly attributed to the hippocampus. The gap between the CS and the US in trace conditioning might engage working memory. However, this seems unlikely. The gaps in trace conditioning of the NM response are brief, only a few hundred milliseconds in length, as compared with the retention intervals of seconds and minutes that are used in delayed matching-to-sample studies of working memory (Kesner, 1982; Rawlins, 1985). 
It seems even less likely that the single, brief stimulus in trace conditioning would engage complex processes of selective attention and/or configuration thought to be mediated by the hippocampus (see, e.g., Kesner, 1982; Moore \& Stickney, 1980; Rudy \& R. J. Sutherland, 1995; R. J. Sutherland \& Rudy, 1989). There is, however, evidence that the onset and offset of even a brief event can serve as separate CSs and, hence, could form a compound of the type that may require complex processing. Desmond and Moore (1991) have shown that the onset and offset of a tone can each command a distinctive CR. They trained rabbits, using a $150-\mathrm{msec}$ tone followed by a 200 -msec trace interval prior to the US. Thus, the CSUS interval for tone onset was $350 \mathrm{msec}$, and the CS-US interval for tone offset was $150 \mathrm{msec}$. When the onset and offset of the tone were separated by extending the tone's duration on test trials, both stimulus events elicited their own CRs. That is, two CRs appeared, one following tone onset and the other following tone offset.

In light of Desmond and Moore's (1991) findings, a trace CS might be viewed as a serial compound. If so, the sensitivity of trace conditioning to hippocampal damage is consistent with the sensitivity of delayed matching-tosample and other conditional discriminations, which also entail the serial presentation of stimuli (Rawlins, 1985; Ross, Orr, Holland, \& Berger, 1984; R. J. Sutherland \& Rudy, 1989). However, it remains to be determined whether trace CSs engage the same mechanisms as do other serial compounds. The present experiments tested trace conditioning, using procedures analogous to those used previously with serial compounds of tone and light CSs (Kehoe, 1987).

\section{EXPERIMENT 1}

If a trace CS acts as a serial compound, it is a prime candidate for a stimulus selection effect know as temporal primacy. When this effect occurs, the first stimulus (CSA) in a series tends to gain associative strength to the detriment of the second stimulus (CSB), even though CSB is more contiguous to the US (Egger \& Miller, 1962; Kehoe, 1983, 1987; Wickens, 1965). In trace conditioning, tone onset would serve as CSA, and tone offset would serve as CSB. Thus, Experiment 1 was conducted to determine whether a temporal primacy effect would appear in trace conditioning.

The experiment contained two groups. In both groups, tone offset (CSB) preceded the US by a trace interval of $400 \mathrm{msec}$. For the rabbit NM preparation, this interval is close to optimal for CR acquisition (Gormezano, Kehoe, \& Marshall, 1983; Kehoe, Cool, \& Gormezano, 1991; Smith, 1968). In one group, the interval between tone onset (CSA) and tone offset (CSB) was $400 \mathrm{msec}$. In the other group, this interval was $3,200 \mathrm{msec}$. In studies using tone and light sequences, a $400-\mathrm{msec}$ CSA-CSB interval tends to impair responding to CSB. Longer CSA-CSB intervals, however, have not impeded responding to CSB (see, e.g., Kehoe, Gibbs, Garcia, \& Gormezano, 1979; Schreurs, Kehoe, \& Gormezano, 1993). Unlike studies using tone and light sequences, it was not possible to test responding to tone offset in complete isolation from tone onset. However, to achieve relative isolation, test trials were conducted in which tone onset and tone offset were separated by $30,000 \mathrm{msec}$.

\section{Method}

Subjects

The subjects were 16 naive, male and female albino rabbits (Oryctolagus cuniculus), each 70-80 days old and weighing approximately $1.5 \mathrm{~kg}$ on arrival from the university's supplier. The animals had free access to food and water in their home cages.

\section{Apparatus}

The apparatus and recording procedure for the NM response were patterned after those of Gormezano (1966) and are detailed by Kehoe, Feyer, and Moses (1981). The CS was a 89-dB (SPL), 1000$\mathrm{Hz}$ tone superimposed on an ambient noise level of $81 \mathrm{~dB}$. The US was a $200-\mathrm{msec}, 3-\mathrm{mA}, 50-\mathrm{Hz}$ ac electrical current delivered via stainless steel Autoclip wound clips positioned $10 \mathrm{~mm}$ apart and $15 \mathrm{~mm}$ posterior to the dorsal canthus of the right eye. The sequence and timing of stimulus events were controlled by an Apple II computer equipped with interfaces and software developed by Scandrett and Gormezano (1980).

To monitor movements of the NM, a small tinned copper wire hook was attached to a silk loop sutured in the NM of the rabbit's right eye. The other end of the hook contained a loop that fitted over the curved end of a L-shaped piano wire crank, which operated a photoelectric transducer (Gormezano \& Gibbs, 1988). The signal from the transducer was amplified and transmitted to an analog/ digital converter installed in the computer.

\section{Procedure}

All the rabbits received 1 day of preparation, 2 days of recovery, 1 day of adaptation, and 12 days of training. On the preparation day, hair surrounding the rabbit's right eye was removed, a small silk loop (000 Dynex) was sutured into the NM, and the animals were returned to their home cages for 2 days of recovery. On the adaptation day, the animals were placed in the conditioning apparatus for $60 \mathrm{~min}$, but neither a CS nor a US was presented.

Following adaptation, the animals were assigned randomly to two groups $(n=8)$, designated as Group 400 and Group 3,200. On CS-US trials, Group 400 received a $400-\mathrm{msec}$ tone followed by a $400-\mathrm{msec}$ trace interval prior to the US. Group 3,200 received a $3,200-\mathrm{msec}$ tone followed by a $400-\mathrm{msec}$ trace interval prior to the US. There were also two types of CS-alone test trials. On standardduration test trials, the tone was the same duration as that used on training trials - that is, $400 \mathrm{msec}$ for Group 400 and 3,200 msec for Group 3,200. On extended-tone test trials, both groups received a 30,000 -msec presentation of the tone. On each day, both groups received $60 \mathrm{CS}-\mathrm{US}$ trials, 3 standard-duration test trials, and 3 extended-tone test trials. A test trial occurred after every 11 th CS-US trial. Each block of 22 trials had one standard-duration test and one extended-tone test. The mean intertrial interval (ITI), as measured from the start of one trial to the start of the next, was $60 \mathrm{sec}$ (range, $50-70 \mathrm{sec}$ ).

\section{Response Definition}

On paired trials, a CR was defined as any extension of the NM exceeding $0.5 \mathrm{~mm}$, initiated between tone onset and US onset (MarshallGoodell, Schreurs, \& Gormezano, 1982). On standard-duration test trials, the observation interval was extended to $3,600 \mathrm{msec}$ after 
tone offset. On extended-tone test trials, there were two 3,600-msec observation periods for CRs, one following tone onset and another following tone offset. Unless otherwise noted, planned contrasts were used to analyze the data, and the rejection level was set according to a Type I error rate of .05 .

\section{Results}

\section{Total CRs}

Figure 1's upper left panel (A) shows the mean percentage of paired trials containing a $C R$ initiated during the total observation period between tone onset and US onset. The means are plotted as a function of 2-day blocks of training. As can be seen, the overall acquisition of the CR proceeded in a similar fashion for both groups. Both groups attained an asymptotic level of around 90\% CRs by the third block of training. Any apparent differences between the groups were not statistically significant. (Virtually identical results were obtained from the standardduration test trials.)

\section{Tone Onset}

The upper right panel (B) of Figure 1 depicts the percentage of extended-tone trials containing a CR within $3,600 \mathrm{msec}$ following tone onset. Group 400 appeared to show a higher level of responding than Group 3,200.
Across all days, Group 400 showed a mean level of $46 \%$ CRs $(S E=11 \%)$, whereas Group 3,200 showed a mean level of only $25 \% \mathrm{CRs}(S E=14 \%)$. However, responding in both groups was variable. The overall difference between Group 400 and Group 3,200 approached but failed to reach the declared level of significance $[F(1,14)=$ $3.79, p=.07]$.

Responding following tone onset on paired trials was also examined. The computation of percentage CRs was based on CRs initiated during the $400-\mathrm{msec}$ tone in Group 400 and during the 3,200-msec tone in Group 3,200. In contrast to test trials, the apparent differences between groups was reversed. On paired trials, Group 400 showed a mean level of $25 \% \mathrm{CRs}(S E=9 \%$ ), whereas Group 3,200 showed an overall mean level of $41 \%$ CRs $(S E=9 \%)$. However, this apparent difference also failed to reach statistical significance.

\section{Tone Offset}

Large and significant differences did appear in responding following tone offset. Responding following tone offset was examined for both paired trials and extendedtone trials. For paired trials, the lower left panel (C) of Figure 1 shows the percentage of trials with CRs initiated during the $400-\mathrm{msec}$ trace interval between tone off-

PAIRED TRIALS: TOTAL INTERVAL
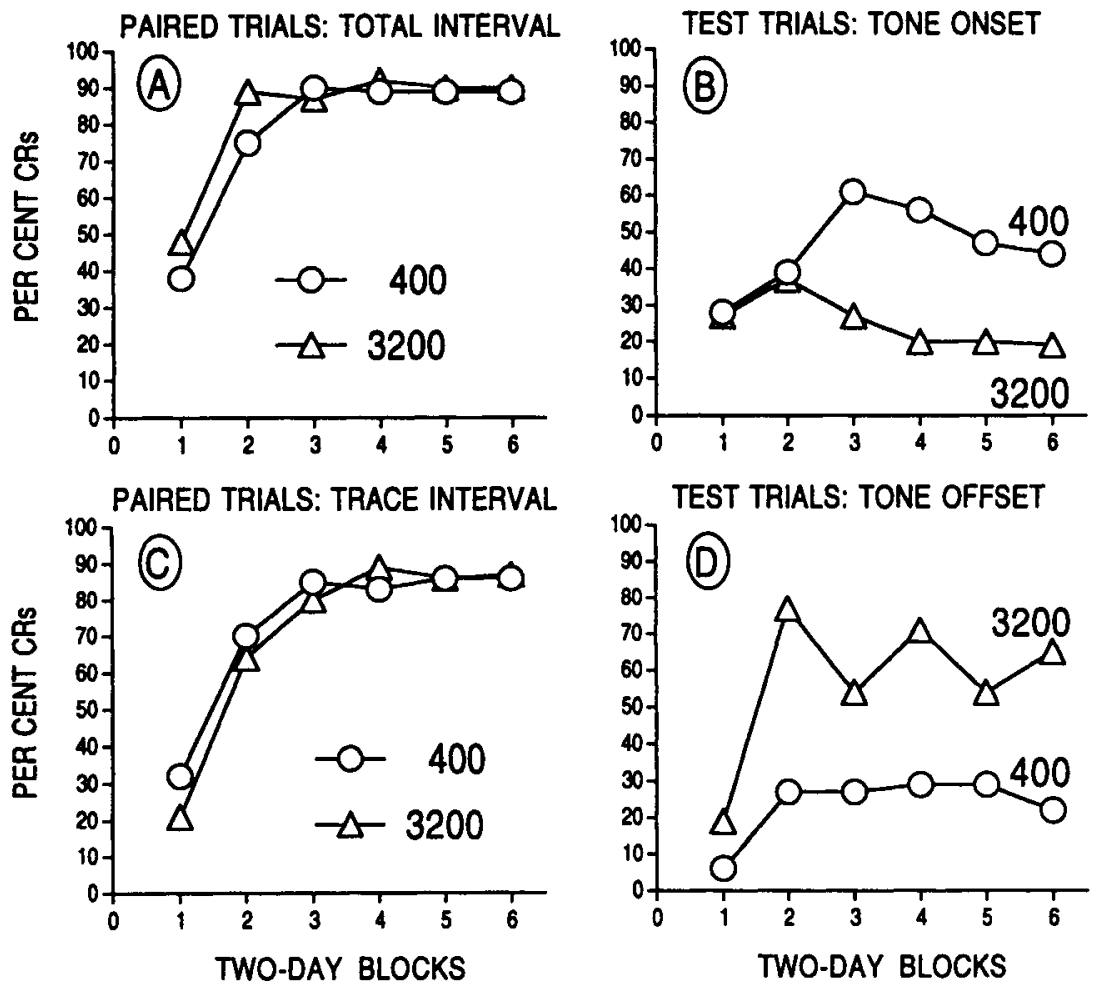

Figure 1. Mean percent conditioned responses (CRs) shown by Groups 400 and 3,200 in Experiment 1 as a function of 2-day blocks. The group labels indicate the tone duration in milliseconds on paired trials. Panel A: CRs during the entire interval between tone onset and US onset on paired trials. Panel B: CRs initiated within 3,600 msec following tone onset on test trials. Panel C: CRs initiated during trace interval on paired trials. Panel D: CRs initiated within 3,600 msec following tone offset on test trials. 
set and US onset. In calculating this percentage, it was necessary to exclude trials on which a CR had been initiated during the tone, because partial or complete closure of the NM often persisted into the trace interval and obscured any additional responses. For test trials, the lower right panel (D) of Figure 1 shows the percentage of trials with CRs initiated within $3,600 \mathrm{msec}$ following tone offset.

On paired trials, both groups showed pronounced CR acquisition during the trace interval. The likelihood of CRs rose across the days of training and reached an asymptote of around $85 \%$ CRs. The overall mean levels of responding in Group $400(M=73 \% \mathrm{CRs}, S E=10 \%)$ and Group 3,200 $(M=71 \% \mathrm{CRs}, S E=12 \%)$ were very similar. Any apparent differences between the two groups were not significant.

On the 30,000-msec test trials, however, responding following tone offset in Group 400 dropped dramatically; the level of responding never rose above $35 \% \mathrm{CRs}$. In contrast, Group 3,200's responding was similar to that seen on paired trials. Its level of responding rose to an asymptote of around $65 \%$ CRs. Statistical comparisons confirmed that Group 400's overall mean level of responding on test trials ( $M=23 \% \mathrm{CRs}, S E=12 \%$ ) was significantly less than that of Group 3,200 $[M=56 \%$ CRs, $S E=14 \%$; $F(1,14)=11.30, p<.05]$.

\section{CR Timing}

The timing of the CRs was examined to determine whether the differences between the two groups in their CR likelihoods were accompanied by changes in CR timing. In trace and delay conditioning in the rabbit NM preparation, CS tests have revealed that the peak of the CR occurs around the time of US delivery on CS-US trials (e.g., Coleman \& Gormezano, 1971; Kehoe \& Napier, 1991; Smith, 1968). Similarly, in the present experiment, the CR peaks on standard-duration tests were tightly concentrated around the point of US delivery. Specifically, $83 \%$ of Group 400 's peaks and $91 \%$ of Group 3,200's peaks occurred with $\pm 200 \mathrm{msec}$ of US delivery. On the extended-tone tests, the location of CR peaks became more dispersed but remained clustered at times corresponding to US delivery, relative to either tone onset or tone offset. During the observation interval following tone onset, $72 \%$ of Group 400's peaks occurred around the 800 -msec point ( $\pm 400 \mathrm{msec})$, and $45 \%$ of Group 3,200's peaks occurred around the 3,600-msec point $( \pm 400 \mathrm{msec})$. Similarly, during the observation interval following tone offset, $52 \%$ of Group 400 's peaks and $90 \%$ of Group 3,200's peaks occurred around the 400 -msec point $( \pm 400 \mathrm{msec})$.

\section{Discussion}

The present experiment revealed a strong temporal primacy effect within trace conditioning. That is, in Group 400, when tone offset was tested in relative isolation from tone onset, there was only weak responding.
However, there was substantial responding to tone onset. Other aspects of the results also matched those seen previously in experiments using serial compounds composed of two distinct events--namely, tone and light. First, a long CSA-CSB interval usually diminishes the temporal primacy effect (Kehoe et al., 1979; Schreurs et al., 1993). In the present experiment, in Group 3,200, responding following tone offset on test trials was nearly as high as it was on training trials. Second, the temporal primacy effect appeared only when CSA and CSB were tested on separate trials (Kehoe, 1979). That is, responding during CSB in a CSA-CSB-US training trial shows acquisition to a high level. Likewise, in Group 400, responding during the trace interval showed acquisition to a high level. Third, the CSB-US interval determines the overall rate of CR acquisition (Kehoe, 1979, 1983). This also appears to have been true in the present experiment. The trace interval between tone offset and the US was fixed at $400 \mathrm{msec}$, whereas the intervals between tone onset and the US differed dramatically between Group 400 and Group 3,200. The rate of CR acquisition on paired trials was similar for the two groups. Had the interval between tone onset and the US governed CR acquisition, much slower CR acquisition would have occurred, particularly in Group 3,200 (Kehoe, 1979).

\section{EXPERIMENT 2}

The temporal primacy effect and its attendant features present a paradox. In Group 400 , tone offset did not command responding in its own right but may have governed overall CR acquisition. Consequently, Experiment 2 had two chief aims. First, it was aimed at replicating Group 400 from Experiment 1, to determine the reliability of the temporal primacy effect. Second, the experiment was designed to ascertain the rate and asymptote of $\mathrm{CR}$ acquisition during the trace interval when only tone offset was available as a CS. Accordingly, the experiment included a control group that received trace conditioning using a 30,000-msec tone, in which pairings of tone offset with the US were largely isolated from tone onset.

The third aim of Experiment 2 was to determine whether the temporal primacy effect in trace conditioning is a species of overshadowing, in which the competition between two stimuli is governed by their relative salience (Kamin, 1969; Pavlov, 1927, p. 141). In order to do this in the present experiment, two tones of different intensity were used. Operationally, tone onset and tone offset entail the same change in physical energy, just in opposite directions. From this perspective, manipulation of tone intensity might be expected to alter only the overall rate of $C R$ acquisition but not to affect the relative salience of tone onset versus tone offset. However, a weaker tone intensity might better balance the relative salience of the tone offset stimulus vis-à-vis tone onset and thereby lessen the temporal primacy effect (cf. Mackintosh, 1976). 
The present experiment compared two tone intensities, specifically, the 89-dB value used previously in Experiment 1 versus a relatively weak $79-\mathrm{dB}$ value (Kehoe, 1982, 1983).

\section{Method \\ Subjects \\ The subjects were 32 naive, male and female albino rabbits.}

\section{Apparatus and Procedure}

Unless otherwise indicated, the apparatus and the procedures were identical to those of Experiment 1. After preparation, the animals were randomly assigned to four groups that comprised a $2 \times 2$ factorial manipulation of tone duration and tone intensity. The two tone durations were $400 \mathrm{msec}$ and $30,000 \mathrm{msec}$, and the two intensities were $79 \mathrm{~dB}$ and $89 \mathrm{~dB}$ (SPL). The groups were designated as $4 / 79,4 / 89,300 / 79$, and $300 / 89$. The first part of the label refers to the tone duration in hundreds of milliseconds, and the second part of the label refers to tone intensity.

\section{Total CRs}

Figure 2's upper left panel (A) shows the acquisition curves for CRs initiated during a 3,600-msec observation period on paired trials. For Groups $300 / 79$ and 300/89, this observation period included the final $3,400 \mathrm{msec}$ of the 30,000 -msec tone, plus the 400 -msec trace interval prior to the US. In order to equate the opportunity to observe responding in Groups 4/79 and 4/89, a 3,600-msec observation period was also used on paired trials. This period included a $2,800-\mathrm{msec}$ portion of the ITI just prior to tone onset, the 400-msec tone itself, and the $400-\mathrm{msec}$ trace interval.

Examination of Figure 2 reveals that both the duration and the intensity of the tone affected CR acquisition in a positive fashion. That is, Group 4/79 showed the slowest CR acquisition, whereas Group 300/89 showed the most rapid CR acquisition. Groups 4/89 and 300/79 showed intermediate rates of CR acquisition. Moreover, the asymptotic levels of responding appeared to show a similar pattern. Overall, Groups 4/79, 4/89, 300/79, and 300/89 showed mean levels of $45 \%, 60 \%, 61 \%$, and $75 \%$ CRs, respectively (largest $S E=12 \%$ ).

Statistical comparisons confirmed that there were main effects of both tone duration and tone intensity $[F \mathrm{~s}(1,28)=$ 6.04 and $6.56, p s<.05]$. These main effects appeared to be additive and consistent across days. That is, they did not
PAIRED TRIALS: TOTAL CRS

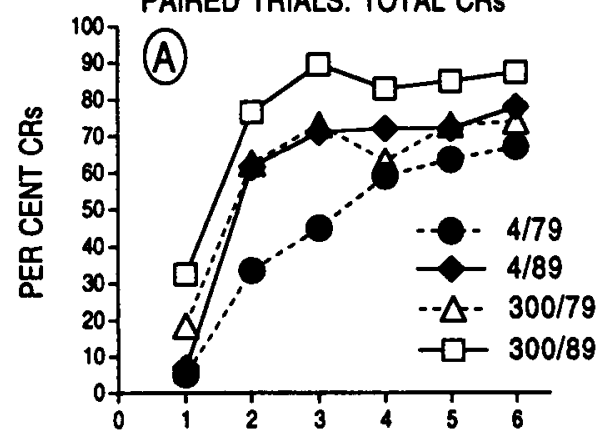

PAIRED TRIALS: TRACE INTERVAL

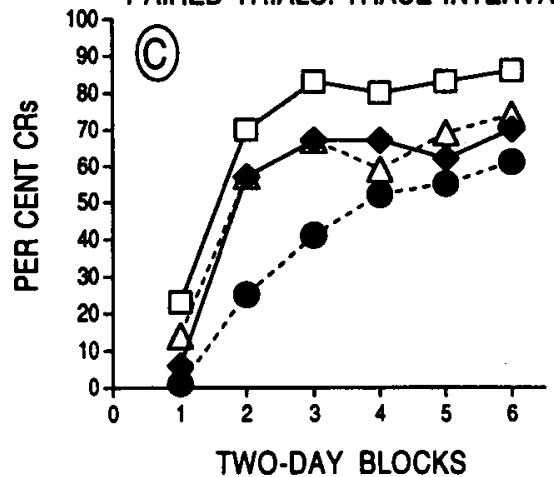

TEST TRIALS: TONE ONSET

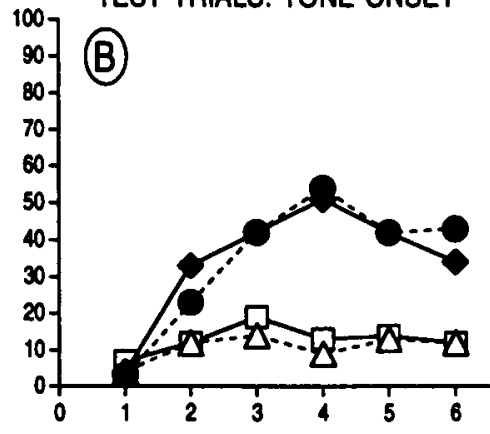

TEST TRIALS: TONE OFFSET

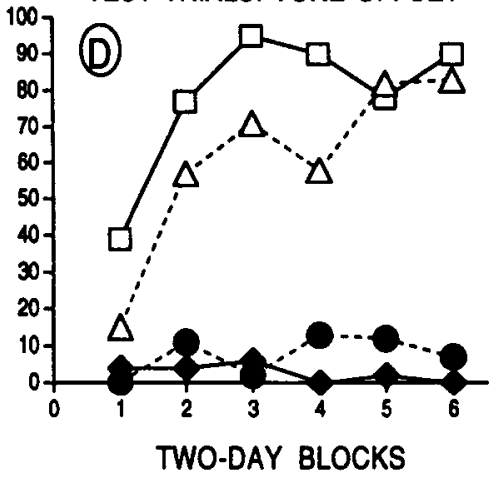

Figure 2. Mean percent conditioned responses (CRs) in Experiment 2 as a function of 2-day blocks. The group labels indicate the tone duration in hundreds of milliseconds (400 vs. 30,000 msec) and the tone intensity in decibels (79 vs. $89 \mathrm{~dB})$. Panel A: CRs during the entire interval between tone onset and US onset on paired trials. Panel B: CRs initiated within 3,600 msec following tone onset on test trials. Panel C: CRs initiated during trace interval on paired trials. Panel D: CRs initiated within 3,600 msec following tone offset on test trials. 
interact with each other or with the linear and quadratic trends across days, which were significant $[F \mathrm{~s}(1,28)=$ 153.48 and $71.21, p s<.05]$.

\section{Tone Onset}

The upper right panel (B) of Figure 2 depicts the percentage of trials containing a CR following tone onset on test trials. Both Group 4/79 and Group 4/89 showed clear acquisition of CRs to tone onset, to levels around $45 \%$ CRs. In contrast, Groups $300 / 79$ and 300/89 showed only modest evidence of CR acquisition. Their level of responding never exceeded $20 \%$ CRs. Overall, Groups $4 / 79,4 / 89,300 / 79$, and 300/89 showed mean levels of $34 \%, 34 \%, 10 \%$, and $12 \%$ CRs, respectively (largest $S E=13 \%)$.

Statistical analyses confirmed that there was a significant main effect of tone duration $[F(1,28)=15.62, p<$ $.05]$. As can be seen in the divergence of the CR acquisition curves, the tone duration also interacted with the linear and quadratic trends across days $\left[F_{\mathrm{S}}(1,28)=17.97\right.$ and $11.34, p \mathrm{~s}<.05]$. Any apparent differences related to tone intensity were small, nonsystematic, and nonsignificant.

\section{Tone Offset}

The lower left panel (C) of Figure 2 shows the percentage of paired trials with CRs initiated during the $400-\mathrm{msec}$ trace interval between tone offset and US onset. As may be apparent, the vast majority of CRs were initiated during the trace interval, and, not surprisingly, the pattern of CR acquisition during the trace interval was very similar to the pattern of overall CR acquisition. All four groups showed $\mathrm{CR}$ acquisition during the trace interval as a positive function of both the duration and the intensity of the tone. Overall, Groups $4 / 79,4 / 89,300 / 79$, and $300 / 89$ showed mean levels of $39 \%, 55 \%, 56 \%$, and $71 \%$ CRs, respectively (largest $S E=13 \%$ ). Statistical comparisons confirmed that there were main effects of both tone duration and tone intensity $[F \mathrm{~s}(1,28)=7.54$ and $6.12, p \mathrm{~s}<.05]$. Neither of them interacted with each other or with the linear and quadratic trends across days $[F \mathrm{~s}(1,28)=87.84$ and $66.79, p \mathrm{~s}<.05]$.

The lower right panel (D) of Figure 2 shows the percentage of test trials with CRs initiated following tone offset. In Groups 4/79 and 4/89, the extension of the tone on test trials reduced responding after tone offset to negligible levels. Responding never exceeded $15 \%$ CRs in any 2-day block of training. In contrast, for Groups 300/79 and $300 / 89$, the duration of the tone on test trials was the same as that on paired trials. Not surprisingly, they showed the same acquisition curves as they had on paired trials. Overall, Groups 4/79, 4/89, 300/79, and 300/89 showed mean levels of $7 \%, 3 \%, 61 \%$, and $78 \%$ CRs, respectively (largest $S E=14 \%$ ).

Statistical comparisons confirmed that Groups 4/79 and 4/89 together showed a lower level of responding following tone offset on test trials than Groups 300/79 and $300 / 89[F(1,28)=163.37, p<.05]$. Because this differ- ence increased in size across training, the main effect of tone duration also interacted with the linear and quadratic trends across days $[F \mathrm{~s}(1,28)=91.27$ and $10.32, p<.05]$. There was also a significant two-way interaction between tone intensity and tone duration $[F(1,28)=4.59, p<.05]$ and a significant three-way interaction between tone intensity, tone duration, and days [linear; $F(1,28)=10.32$, $p<.05$ ]. These interactions can be attributed to the difference in responding in Group 300/79 versus Group 300/89, in combination with the virtual absence of responding in either Group 4/79 or Group 4/89.

\section{Discussion}

The results of Experiment 2 confirmed that temporal primacy occurs in trace conditioning. That is, deficits in responding to tone offset appeared on test trials in Groups $4 / 79$ and $4 / 89$, which had been trained with a short-duration tone on paired trials. Experiment 2 fulfilled its second aim of demonstrating that tone offset by itself could effectively act as a CS. That is, in Groups 300/79 and $300 / 89$, in which tone onset was well removed from the US, there was substantial CR acquisition on the basis of the contiguity of tone offset to the US. In fact, these groups showed significantly faster $\mathrm{CR}$ acquisition than did Groups 4/79 and 4/89, in which tone onset was far closer to the US.

This latter finding - faster CR acquisition in Groups $300 / 79$ and 300/89 than in Groups 4/79 and 4/89-was unexpected. On reflection, there are two possible sources for this effect. First, because tone onset and tone offset are in the same sensory modality, they may interfere with each other's encoding when close together on training trials. In Groups $4 / 79$ and 4/89, the encoding of tone onset may not be complete within $400 \mathrm{msec}$ and, hence, may inhibit the encoding of tone offset. There is converging evidence for within-modality interference in the rabbit NM literature. Specifically, a compound of two CSs from different sensory modalities (e.g., tone + light) will summate to produce a high level of responding, but a compound of two CSs from the same modality (e.g., tone + white noise) fails to summate and yields a level of responding only as high as the stronger of the two CSs (Kehoe, Horne, Horne, \& Macrae, 1994).

As an alternative to this interference hypothesis, the longer tone in Groups 300/79 and 300/89 may contribute to overall CS intensity and thereby enhance the rate of CR acquisition (cf. Kehoe, 1982, 1983; Scavio \& Gormezano, 1974; Solomon, Brennan, \& Moore, 1974). On the basis of the available evidence, it would appear unlikely that the sheer duration of the tone energizes the CR. When trace CSs have been extended on test trials, the extension has had a relatively slight impact on responding. In Kehoe and Napier (1991), rabbits trained with a 25-msec CS showed only a slight, nonsignificant decline from $84 \%$ CRs to $72 \%$ CRs when the CS was extended from 25 to $400 \mathrm{msec}$. However, a more speculative possibility is that the long tone duration produces some sen- 
sory adaptation, so that the tone offset is effectively a more intense stimulus than when it more closely follows tone onset in Groups 4/79 and 4/89.

Experiment 2 was less successful in revealing whether reductions in tone intensity would reduce the temporal primacy effect. The manipulation of tone intensity was effective insofar as it had a significant effect on overall CR acquisition during paired trials. As might be expected, the 79-dB tone produced a lower rate of $\mathrm{CR}$ acquisition than the 89-dB tone. However, the temporal primacy effect appeared equally robust in Groups 4/79 and 4/89. Responding to tone offset was so low that a floor effect may have obscured any effect of tone intensity.

\section{EXPERIMENTS 3 AND 4}

Experiments 3 and 4 were conducted to determine whether prior training with tone onset could block CR acquisition to tone offset. Blocking is one of the primary stimulus selection effects and is sensitive to hippocampal damage in the rabbit NM preparation (Solomon, 1977). Blocking is said to occur when prior training with one CS impairs CR acquisition to another CS when it is added later to form a compound stimulus (Kamin, 1968, 1969). Speaking generally, the added CS is redundant with the first CS as a predictor of the US, and, hence, no additional effort is expended in acquiring a CR to the added CS (Kamin, 1969; Mackintosh, 1975; Pearce \& Hall, 1980; Rescorla \& Wagner, 1972; N. S. Sutherland \& Mackintosh, 1971).

In serial compound conditioning experiments, when a CS has been paired with a US, subsequent training of that CS in sequence with a new CS has been found to produce some blocking of the new CS. Specifically, prior training of the first stimulus (CSA) works in concert with the temporal primacy effect to obliterate acquisition of responding to the second stimulus (CSB; Aguado, Lopez, \& Lillo, 1989; Gaioni, 1982; Kehoe, Schreurs, \& Amodei, 1981; Kohler \& Ayres, 1982; Ross \& Lolordo, 1986). Blocking in the reverse case is weaker. That is, prior training with CSB must work against the temporal primacy effect and, at best, yields only modest deficits in response acquisition to CSA (Gibbs, Kehoe, \& Gormezano, 1991; Kehoe, Schreurs, \& Amodei, 1981; Kehoe, Schreurs, \& Graham, 1987).

In Experiments 3 and 4, we tested whether prior training with tone onset would enhance the temporal primacy effect. In both experiments, an experimental group received delay conditioning in Stage 1, in which the tone extended through the entire CS-US interval. Hence, tone offset coincided with US onset and was not available for conditioning (Kehoe, Feyer, \& Moses, 1981; Smith, 1968). In Stage 2, the tone was shortened, so that a $400-\mathrm{msec}$ trace interval was introduced between tone offset and the US. A control group also had delay conditioning in Stage 1, but with a light stimulus rather than with the tone stimulus. This training with the light stimulus was used to equate the control group to the experimental group in terms of their general experience with CS-US pairings. Previous research has indicated that such prior training, even with a stimulus from another modality, does not yield generalization but does enhance the rate of CR acquisition to another CS (Kehoe \& Holt, 1984). Subsequently, this control group received trace conditioning with the same tone as that in the experimental group.

The two experiments differed in the duration of the tone. In Experiment 3, the tone was 3,600 $\mathrm{msec}$ in delay conditioning and $3,200 \mathrm{msec}$ in trace conditioning. In Experiment 4, it was $1,600 \mathrm{msec}$ in delay conditioning and $1,200 \mathrm{msec}$ in trace conditioning. The duration of the tone was dictated by two conflicting demands. On the one hand, the duration had to be long enough that it would produce a moderate but not a complete temporal primacy effect. On the other hand, the CS-US interval for tone onset had to be short enough to yield CR acquisition in Stage 1 and thus potentially block $\mathrm{CR}$ acquisition to tone offset in Stage 2. The longer tone in Experiment 3 minimized the temporal primacy effect but yielded little initial CR acquisition. The shorter tone in Experiment 4 was intended to strike a better balance between the two demands.

\section{Method}

\section{Subjects}

Each experiment used 16 experimentally naive male and female rabbits.

\section{Apparatus and Procedure}

Unless otherwise indicated, the apparatus and procedures were identical to those of Experiment 1. After preparation, the animals in each experiment were randomly assigned to two groups, which received 10 days of Stage 1 training and 10 days of Stage 2 training.

In Experiment 3, the experimental group was labeled Group T36. Its training sessions in Stage 1 contained 60 trials of delay conditioning in which a 3,600-msec tone CS was paired with the US. The control group was labeled Group L36. Its training sessions in Stage 1 contained 60 trials of delay conditioning in which a 3,600-msec light CS was paired with the US. The light CS was a $20-\mathrm{Hz}$ flashing of the 8-w neon tube that served as the houselight. In both groups, the offset of the CS coincided with US onset. In Stage 2, both groups received trace conditioning in which the 3,200-msec tone terminated $400 \mathrm{msec}$ before US onset. Each session contained 60 CS-US trials plus four test presentations of the tone alone for $30 \mathrm{sec}$. A tone-alone trial occurred after every 15 th CS-US trial.

The procedures in Experiment 4 were identical to those of Experiment 3 , except that the CS durations and, accordingly, the CS-US intervals were shorter. Specifically, for the experimental group (Group T 16), the tone CS in Stage 1 delay conditioning was $1,600 \mathrm{msec}$, and, for the control group (Group L16), the light CS was 1,600 msec. In both cases, the CS terminated at US onset. In Stage 2 trace conditioning, the tone CS was $1,200 \mathrm{msec}$ and terminated $400 \mathrm{msec}$ before US onset.

\section{Results}

\section{Stage 1: Delay Conditioning}

In Experiment 3, the 3,600-msec CS-US interval produced modest levels of CR acquisition in delay conditioning. Group T36 attained an asymptotic level of around $45 \% \mathrm{CRs}$, and Group L36 attained an asymptotic level of around $20 \% \mathrm{CRs}$. There was considerable variance both 
within groups and over days. Consequently, the apparent difference between Group T36 $(M=43 \%, S E=10 \%)$ and Group L36 $(M=22 \%, S E=9 \%)$ did not reach significance $[F(1,14)=3.71, p<.10]$. Responding during the final $400 \mathrm{msec}$ of the CS, which corresponded to location of the trace interval in Stage 2, was negligible in both groups. Specifically, Groups T36 and L36 produced mean levels of $4 \%$ CRs $(S E=3 \%)$ and $3 \%$ CRs $(S E=$ $2 \%$ ), respectively, during the final $400 \mathrm{msec}(F<1)$.

The use of a 1,600-msec CS-US interval in Experiment 4 also yielded modest levels of CR acquisition in delay conditioning. Group T16 reached an asymptote of around $60 \% \mathrm{CRs}$, and Group L16 reached an asymptote of $50 \%$ CRs. The overall levels for Group T16 $M=51 \%$, $S E=15 \%)$ and Group L16 $(M=38 \%, S E=11 \%)$ failed to differ significantly $(F<1)$. Examination of responding during the last $400 \mathrm{msec}$ of the tone did reveal appreciable levels of responding. Groups T16 and L16 showed mean levels of $35 \%$ CRs $(S E=13 \%)$ and $25 \%$ CRs $(S E=10 \%)$, respectively $(F<1)$.

\section{Stage 2: Trace Conditioning}

Total CRs. Figure 3's upper left panel (A) shows the acquisition curves for CRs initiated during the total interval between tone onset and US onset on paired trials in Stage 2. As may be apparent, the introduction of the trace interval produced additional increments in CR acquisition in both Group T36 and Group T16. Groups L36 and L16 also showed rapid CR acquisition during trace conditioning with the tone CS. All the groups achieved levels of responding in excess of $70 \%$ CRs. Any apparent differences were not statistically significant.

Tone onset. The upper right panel (B) of Figure 3 depicts the percentage of trials containing a CR following tone onset on test trials. There was considerable variability across days, but there appeared to be a rise followed by a decline in responding to tone onset. The statistical analyses for both experiments yielded a significant quadratic trend in responding across days $[F(1,14)=4.96$ and $37.76, p s<.05$, respectively]. Any differences between the groups within each experiment were not significant.

Tone offset. The lower left panel (C) of Figure 3 shows the percentage of trials with CRs initiated during the 400 msec trace interval between tone offset and US onset on paired trials. As was seen in previous experiments, the pattern of $C R$ acquisition during the trace interval resembled overall $\mathrm{CR}$ acquisition. All the groups reached final levels of $67 \%$ CRs or greater. Any differences between the two groups within each experiment were not significant.
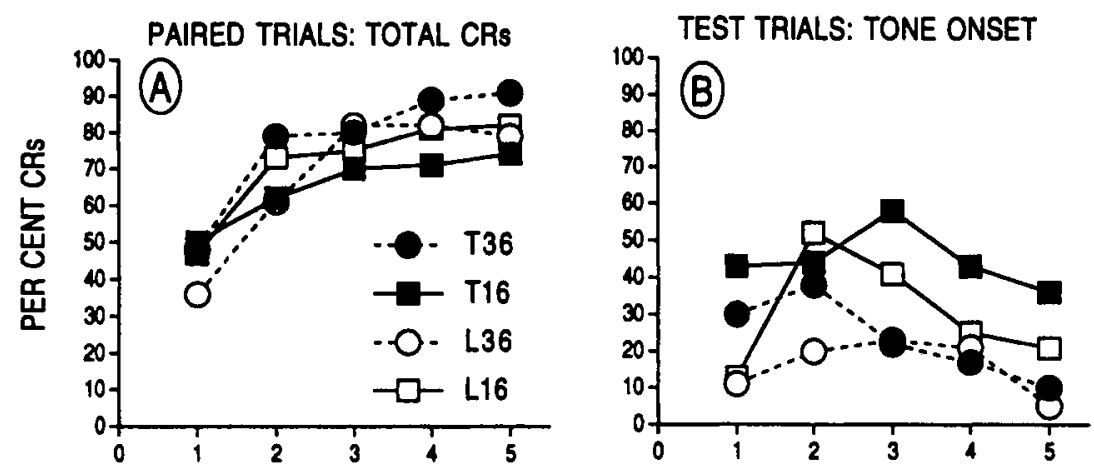

PAIRED TRIALS: TRACE INTERVAL
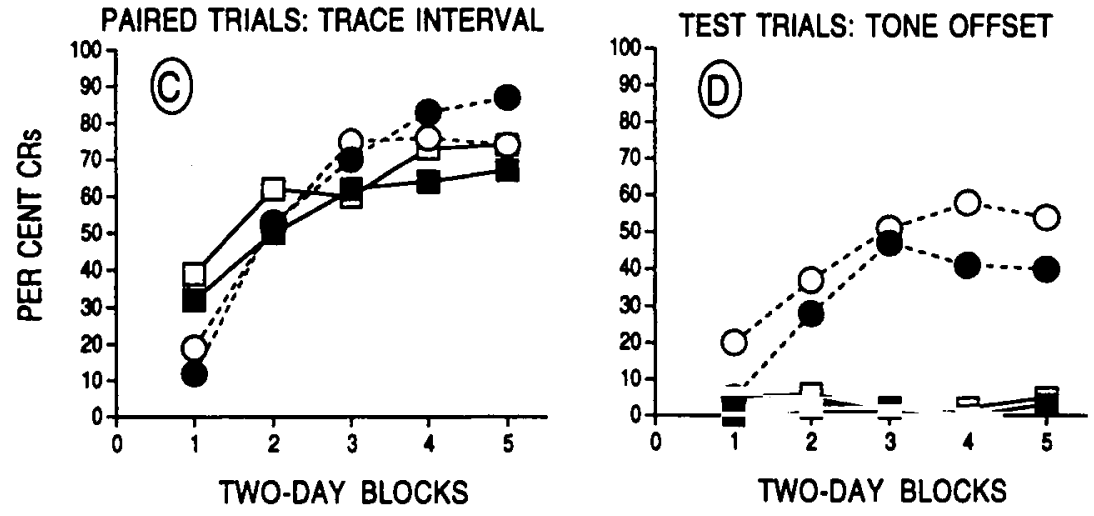

Figure 3. Mean percent conditioned responses (CRs) in Experiments 3 and 4 as a function of 2-day blocks. The group labels indicate the modality of the stimulus in Stage 1 delay conditioning (tone vs. light) and its duration $(3,600$ msec in Experiment 3 , 1,600 msec in Experiment 4). Panel $A$ : CRs during the entire interval between tone onset and US onset on paired trials. Panel B: CRs initiated within 3,600 msec following tone onset on test trials. Panel C: CRs initiated during trace interval on paired trials. Panel D: CRs initiated within 3,600 msec following tone offset on test trials. 
The lower right panel (D) of Figure 3 shows the percentage of trials with CRs initiated following tone offset on test trials. Both Group T36 and Group L36 showed moderate but steady $C R$ acquisition to tone offset. The main effect of days was significant [linear trend, $F(1,14)=$ $14.49, p<.01]$. Compared with the levels of responding following tone offset on paired trials, the final levels of responding on test trials were lower, indicating a weak temporal primacy effect. There was also an indication of a small blocking effect, insofar as Group T36 showed less responding than Group L36. However, the overall difference between Group T36 $(M=32 \%, S E=11 \%)$ and Group L36 $(M=44 \%, S E=13 \%)$ was not statistically significant $[F(1,14)=2.25, p>.10]$. Likewise, there was no significant difference between the two groups in their trends across days.

In Groups $\mathrm{T} 16$ and $\mathrm{L} 16$, it was not possible to ascertain whether any blocking occurred. Responding to tone offset on test trials was virtually nonexistent. Overall, Groups T 16 and $\mathrm{L} 16$ showed $1 \%$ and $4 \%$ CRs (larger $S E=3 \%$ ), respectively. This difference was in the direction of blocking but was not significant $[F(1,14)=3.11, p>.05]$. Any apparent differences between the two groups over days were not significant $(F \mathrm{~s}<1)$.

\section{Discussion}

As was seen in the attempt to demonstrate overshadowing in Experiment 2, the temporal primacy effect made it difficult to ascertain whether prior training with tone onset could block CR acquisition to tone offset. In Experiment 3 , we minimized the temporal primacy effect by conducting training with a relatively long tone. The resulting CS-US interval $(3,600 \mathrm{msec})$ yielded only modest $\mathrm{CR}$ acquisition in initial delay conditioning and apparently insufficient associative strength to block CR ac- quisition to tone offset. In Experiment 4, the tone duration was shortened. We had hoped this duration would yield more initial delay conditioning to tone onset but, in trace conditioning, would produce only a modest temporal primacy effect, thus leaving some room to detect blocking. The 1,600-msec tone did yield the desired level of initial CR acquisition, around $60 \%$ CRs in Group T16. However, when the trace interval was introduced, there was a very strong temporal primacy effect. There was virtually no CR acquisition to tone offset, as measured on test trials, in either Group T16 or Group L16.

\section{GENERAL DISCUSSION}

Across experiments, there was a reciprocal relationship in the level of CR acquisition to tone onset and tone offset as a function of the tone duration. This interaction is summarized in Figure 4. This figure shows the mean CR percentage for (1) the total period from tone onset to US onset on paired trials, which thus included the tone duration and the trace interval, (2) a 3,600-msec period following tone onset on test trials, and (3) a 3,600-msec period following tone offset on test trials. The figure also shows the best-fitting lines for each of the three measures of responding. Because the duration variable has been plotted on a logarithmic scale, two of the lines appear to be curved, but, on an ordinary scale, they would be straight.

As can be seen in Figure 4, the level of total responding was high and constant across all the tone durations. Despite the constant total level of responding, there was a reciprocal relationship in responding to tone onset and tone offset. At shorter tone durations, responding to tone onset was only moderate but, nonetheless, higher than responding to tone offset, which was negligible. At the

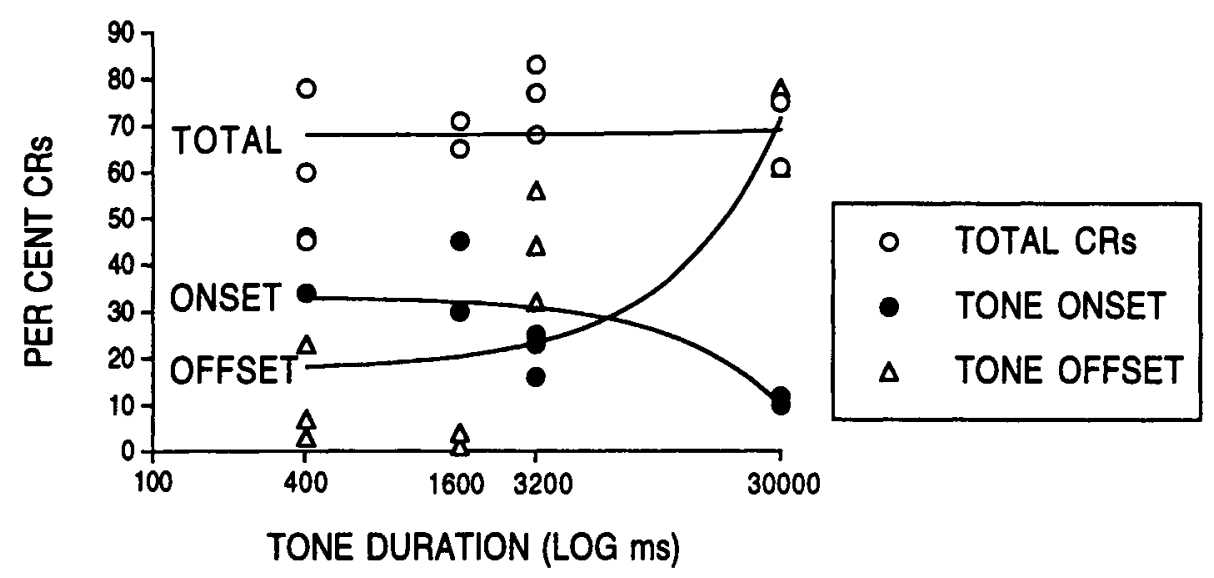

Figure 4. Summary of the mean CR percentages as a function of tone duration on trace conditioning trials (logarithmic scale) for three different periods: (1) total CRs for the entire interval between tone onset and US onset on paired trials, (2) CRs following tone onset on test trials, and (3) CRs following tone offset on test trials. The figure also shows the best-fitting lines for each of the three measures. 
longer tone durations, responding to tone onset declined to low levels, whereas responding to tone offset rose to a level equal to that of the total interval.

The constant total level of responding suggests that the tone offset, which had a relatively contiguous relationship with the US, determined the overall level of CR acquisition. The trace interval was the one fixed feature in training, and the course of CR acquisition resembled what has been found for a 400-msec CSB-US interval in previous rabbit NM studies (e.g., Kehoe, 1979, 1983). There was also internal evidence in the present experiments that the trace interval governed overall CR acquisition. Initial delay conditioning in Experiments 3 and 4 revealed that the CS-US intervals of $3,600 \mathrm{msec}$ and $1,600 \mathrm{msec}$ yielded only modest CR acquisition. Once the 400-msec trace interval was added, additional CR acquisition occurred, and its level quickly reached the same level seen when the trace interval was in place throughout training.

The present results parallel those obtained when a serial compound of tone and light has been used to signal the US. These studies also revealed that total responding to the compound was relatively constant but that there was a reciprocal relationship between responding to CSA and CSB, depending on the CSA-CSB interval (Kehoe et al., 1979; Schreurs et al., 1993). For CSA-CSB intervals of around $400 \mathrm{msec}$, responding to CSB on test trials is much lower than in control groups in which only CSB is paired with the US. For longer CSA-CSB intervals, responding to CSB rose to control levels and exceeded responding to CSA.

One effect obtained in previous studies with serial compounds was not readily apparent in the present results. At longer CSA-CSB intervals, $\mathrm{CR}$ acquisition to CSA is facilitated by the inclusion of CSB to form the CSACSB-US sequence (Kehoe et al., 1979; Kehoe, MarshallGoodell, \& Gormezano, 1987; Kehoe \& Morrow, 1984). This facilitation appears to be a result of second-order conditioning based on the CSA-CSB pairings embedded within the sequence (Gibbs, Cool, Land, Kehoe, \& Gormezano, 1991; Gibbs, Kehoe, \& Gormezano, 1991; Kehoe, Feyer, \& Moses, 1981). In the present results, there was no discernible evidence that $\mathrm{CR}$ acquisition to tone onset benefited from the presence of the trace interval and the consequent $\mathrm{CR}$ acquisition to tone offset. When tone onset was trained without the trace interval in Stage 1 of Experiments 3 and 4, responding to tone onset attained levels of $45 \%$ and $60 \%$ in Groups T36 and T16, respectively. After the introduction of the trace interval in Stage 2, responding to tone onset did not rise and, if anything, tended to drop, even though total responding increased.

The present findings in trace conditioning add to the seemingly paradoxical evidence that the deficits in responding on CSB test trials do not necessarily reflect a failure of CSB to gain associative strength in paired trials. To explain this seeming failure of CSB's associative strength to be expressed, there have been two main the- oretical approaches, both of which are compatible with current thinking about the function of the hippocampus. In broad terms, theories of stimulus selection can be divided into configural and distributive hypotheses (J. H. James \& Wagner, 1980).

\section{Configural Hypotheses}

Configural hypotheses presuppose that an individual CS produces different neural encodings, depending on the context provided by earlier stimuli in a series (Borgealt, Donahoe, \& Weinstein, 1972; Hancock, 1982; Kehoe, 1979, 1983; Kehoe, Schreurs, \& Graham, 1987). By assuming that different encodings of tone offset occur inside, rather than outside, the context provided by tone onset, configural hypotheses can readily explain the present results. Specifically, during trace conditioning with the shorter duration tones, the close succession of tone onset and tone offset would form a configural stimulus that would have full access to the associative apparatus. However, the associative strength of the configural stimulus would generalize only weakly to tests in which tone offset was presented in isolation from tone onset. In contrast, longer duration tones would be less likely to produce a strong configural stimulus entailing tone onset. Accordingly, tone offset would alone gain access to the associative apparatus, and its associative strength would generalize fully to the test trials.

\section{Distributive Hypotheses}

Distributive models contend that there is a tradeoff among compounded stimuli in their ability to gain associative strength through competition for access either to the associative apparatus (Rescorla \& Wagner, 1972) or to attentional resources (Mackintosh, 1975; Moore \& Stickney, 1980; Pearce \& Hall, 1980; N.S. Sutherland \& Mackintosh, 1971). These hypotheses have aimed typically at overshadowing and blocking among simultaneous stimuli. Sutton and Barto (1981, 1990), however, have provided a rigorous account of temporal primacy effects by using a real-time implementation of a distributive rule proposed originally by Rescorla and Wagner. Sutton and Barto contend that learning occurs on a continuous basis, not just at the end of a trial, when the US may or may not occur. Specifically, learning occurs whenever there is a discrepancy between associative strength at one moment and that at the next. In a sequence of stimuli, such discrepancies can arise at the time of other stimulus events, as well as at the time of the US (Desmond, 1990; Desmond \& Moore, 1991).

According to the Sutton-Barto $(1981,1990)$ model, the temporal primacy effect would occur in trace conditioning because tone onset (CSA) effectively "steals" associative strength from tone offset (CSB). Within a CSACSB-US trial, CSA's associative strength $\left(V_{\mathrm{A}}\right)$ gains an increment at the onset of CSB from any associative strength previously gained by $\mathrm{CSB}\left(V_{\mathrm{B}}\right)$. Thus, as quickly as CSB gains associative strength, it would lose it to CSA. Later within a trial, at the point of US onset, both CSA 
and CSB gain associative strength on a competitive basis according to their relative salience. Thus, $V_{\mathrm{A}}$ increases at the onsets of both CSB and the US, whereas $V_{\mathrm{B}}$ increases only at the onset of the US. During the trace interval on paired trials, responding would be high as a result of the summation of $V_{\mathrm{A}}+V_{\mathrm{B}}$. As $V_{\mathrm{A}}$ approaches the asymptotic value, the summated associative strengths $\left(V_{\mathrm{A}}+V_{\mathrm{B}}\right)$ could exceed that sustainable by the US. Consequently, at US onset, there would be decrements in both $V_{\mathrm{A}}$ and $V_{\mathrm{B}}$. On the next trial, $V_{\mathrm{A}}$ would regain its lost value at CSB onset, whereas $V_{\mathrm{B}}$ would continue to suffer decrements at US onset until the sum $V_{\mathrm{A}}+V_{\mathrm{B}}$ stabilizes at a level sustainable by the US. In this manner, tone offset (CSB), being the stimulus more contiguous to the US, would govern the rate of CR acquisition, but tone offset's associative strength would be siphoned off by tone onset (CSA). Consequently, on test trials in which tone offset was isolated from tone onset, only the weakened value of $V_{\mathrm{B}}$ would be available to elicit responding.

\section{Hybrid Hypotheses}

For the purposes of explaining the present findings, either a configural or a distributive process would seem to suffice. Moreover, when considering the wider literature, both processes appear to be necessary. Configural processes are strongly implied by repeated demonstrations that animals can learn to discriminate a compound from its elements. One of the most important of these discriminations is negative patterning, in which the animal learns to respond to the individual elements that are paired with the US $(\mathrm{A}+, \mathrm{B}+)$, while responding to the compound that is presented alone is inhibited $(\mathrm{AB}-;$ Kehoe \& Graham, 1988; Pavlov, 1927, p. 196; Rudy \& R. J. Sutherland, 1989). At the same time, distributive processes appear to underpin blocking and other stimulus selection effects, in which CSs are consistently paired with the US but nevertheless suffer deficits in CR acquisition when compounded with a better predictor of the US (J. H. James \& Wagner, 1980; N. S. Sutherland \& Mackintosh, 1971; Wagner, Logan, Haberlandt, \& Price, 1968).

Acceptance of both configural and distributive hypotheses is hardly an elegant theoretical state of affairs. However, the development of connectionist modeling has provided a basis for a unified explanation of both configural discriminations and stimulus selection effects. Both can be derived from a novel application of distributive principles (see, e.g., Kehoe, 1988; Schmajuk \& DiCarlo, 1992; Schmajuk, Lamoureux, \& Holland, 1998). Connectionist models suppose that there are layers of neuron-like associative units that intervene between sensory input and response output (Barto, Anderson, \& Sutton, 1982; McClelland, Rumelhart, \& Hinton, 1986). The learning rule for each unit is often a version of the distributive principle used previously by Rescorla and Wagner (1972) and Sutton and Barto (1981, 1990). Hence, connectionist models contain no new principles but do use old principles in a novel fashion. Whereas distributive principles have typically been used to explain learning in the organism as a whole, layered network models repeatedly apply them in a dispersed fashion to the local connections among units.

This dispersed use of a distributive learning rule allows units in one layer to compete with each other for the acquisition of associative connections to units in the next layer. Depending on the results of this competition, one sensory input may dominate, thus yielding a stimulus selection effect. Alternatively, two sensory inputs may each acquire a subthreshold excitatory connection with an intermediate unit, so that only their combination will trigger the intermediate unit. In this case, the unit comes to act as configural representation, which can then acquire excitatory or inhibitory connections with units in the next layer. In this way, a layered network can yield both selective and configural outcomes in a systematic fashion. Moreover, the increasing ability of layered network models to explain all these phenomena may help illuminate the neural architecture and processes of the hippocampus and its relation to other pathways for conditioning (see, e.g., Gluck \& Myers, 1997; Myers \& Gluck, 1994; Schmajuk \& Moore, 1988).

\section{Conclusions}

The present results provide converging evidence for previous findings that, in trace conditioning, tone offset can be a salient CS in its own right (Desmond \& Moore, 1991). Moreover, the results demonstrate that trace conditioning is governed by much the same processes as more conventional serial compounds. In particular, the interaction between tone onset and tone offset yields a robust temporal primacy effect. In conclusion, trace conditioning might seem to be a prototype of simple conditioning but, in fact, is more safely viewed as a complex form of conditioning. At the same time, this conclusion helps to simplify the picture of hippocampal function. Because the trace CS is effectively a compound stimulus, trace conditioning now fits more easily with other phenomena, such as blocking and negative patterning, that are susceptible to hippocampal damage.

\section{REFERENCES}

AguAdo, L., LoPEZ, M., \& LiLlo, J. (1989). Blocking with serial compound stimuli: The role of local context and second-order associations. Quarterly Journal of Experimental Psychology, 41 B, 3-19.

Anderson, B. J., \& SteinmeTZ, J. E. (1994). Cerebellar and brainstem circuits involved in classical eyeblink conditioning. Reviews in the Neurosciences, 5, 251-273.

Barto, A. G., Anderson, C. W., \& Sutton, R. S. (1982). Synthesis of nonlinear control surfaces by a layered associative search network. Biological Cybernetics, 43, 175-185.

Borgealt, A. J., Donahoe, J. W., \& Weinstein, A. (1972). Effects of delayed and trace components of a compound CS on conditioned suppression and heart rate. Psychonomic Science, 26, 13-15.

Coleman, S. R., \& Gormezano, I. (1971). Classical conditioning of the rabbit's (Oryctolagus cuniculus) nictitating membrane response under symmetrical CS-US interval shifts. Journal of Comparative \& Physiological Psychology, 77, 447-455. 
DESMOND, J. E. (1990). Temporal adaptive responses in neural models: The stimulus trace. In M. Gabriel \& J. W. Moore (Eds.), Learning and computational neuroscience (pp. 421-456). Cambridge, MA: MIT Press.

Desmond, J. E., \& Moore, J. W. (1991). Altering the synchrony of stimulus trace processes: Tests of a neural-network model. Biological Cybernetics, 65, 161-169.

EGger, D. M., \& MilleR, N. E. (1962). Secondary reinforcement in rats as a function of information value and reliability of the stimulus. Journal of Experimental Psychology, 64, 174-184.

GAIONI, S. J. (1982). Blocking and nonsimultaneous compounds: Comparison of responding during compound conditioning and testing. Pavlovian Journal of Biological Sciences, 17, 16-29.

Gibis, C. M., Cool, V., Land, T., Kehoe, E. J., \& Gormezano, I. (1991). Second-order conditioning of the rabbit's nictitating membrane response: Interstimulus interval and frequency of CS-CS pairings. Integrative Physiological \& Behavioral Science, 26, 282-295.

GibBs, C. M., KehoE, E. J., \& Gormezano, I. (1991). Conditioning of the rabbit's nictitating membrane response to a CSA-CSB-US serial compound: Manipulations of CSB's associative character. Journal of Experimental Psychology: Animal Behavior Processes, 17, 423-432.

GLuCK, M. A., \& MYERS, C. E. (1997). Psychobiological models of hippocampal function in learning and memory. Annual Review of Psychology, 48, 481-514.

Gormezano, I. (1966). Classical conditioning. In J. B. Sidowski (Ed.), Experimental methods and instrumentation in psychology (pp. 385420). New York: McGraw-Hill.

Gormezano, I., \& GibBs, C. M. (1988). Transduction of the rabbit's nictitating membrane response. Behavior Research Methods, Instruments, \& Computers, 20, 18-21.

Gormezano, I., Kehoe, E. J., \& Marshall, B. S. (1983). Twenty years of classical conditioning research with the rabbit. In J. M. Sprague \& A. N. Epstein (Eds.), Progress in psychobiology and physiological psychology (pp. 197-275). New York: Academic Press.

HANCOCK, R. A., JR. (1982). Tests of the conditioned reinforcement value of sequential stimuli in pigeons. Animal Learning \& Behavior, 10, 46-54.

James, G. O., Hardiman, M. J., \& Yeo, C. H. (1987). Hippocampal lesions and trace conditioning in the rabbit. Behavioural Brain Research, 23, 109-116.

JAMES, J. H., \& WAGNER, A. R. (1980). One-trial overshadowing: Evidence of distributive processing. Journal of Experimental Psychology: Animal Behavior Processes, 6, 188-205.

KAMIN, L. J. (1968). "Attention-like" processes in classical conditioning. In M. R. Jones (Ed.), Miami symposium on the prediction of behavior: Aversive stimulation (pp. 9-31). Miami. FL: University of Miami Press.

KAMIN, L. J. (1969). Predictability, surprise, attention, and conditioning. In B. Campbell \& R. Church (Eds.), Punishment and aversive behavior (pp. 279-296). New York: Appleton-Century-Crofts.

KeHOE, E. J. (1979). The role of CS-US contiguity in classical conditioning of the rabbit's nictitating membrane response to serial stimuli. Learning \& Motivation, 10, 23-38.

KEHOE, E. J. (1982). Overshadowing and summation in compound stimulus conditioning of the rabbit's nictitating membrane response. Journal of Experimental Psychology: Animal Behavior Processes, 8 , 313-328.

KeHOE, E. J. (1983). CS-US contiguity and CS intensity in conditioning of the rabbit's nictitating membrane response to serial compound stimuli. Journal of Experimental Psychology: Animal Behavior Processes, 9, 307-319.

KeHOE, E. J. (1987). "Selective association" in compound stimulus conditioning with the rabbit. In I. Gormezano,W. F. Prokasy, \& R. F. Thompson (Eds.), Classical conditioning II (3rd ed., pp. 161-196). Hillsdale, NJ: Erlbaum.

KeHOE, E. J. (1988). A layered network model of associative learning: Learning-to-learn and configuration. Psychological Review, 95, 411-433.

Kehoe, E. J., Cool, V., \& Gormezano, I. (1991). Trace conditioning of the rabbit's nictitating membrane response as a function of CS-US interstimulus interval and trials per session. Learning \& Motivation, 22, 269-290.
Kehoe, E. J., Feyer, A.-M., \& Moses, J. L. (1981). Second-order conditioning of the rabbit's nictitating membrane response as a function of the CS2-CS1 and CS1-US intervals. Animal Learning \& Behavior, 9, 304-315.

Kehoe, E. J., Gibrs, C. M., Garcia, E., \& Gormezano, I. (1979). Associative transfer and stimulus selection in classical conditioning of the rabbit's nictitating membrane response to serial compound CSs. Journal of Experimental Psychology: Animal Behavior Processes, 5, 1-18.

KehoE, E. J., \& Graham, P. (1988). Summation and configuration in negative patterning of the rabbit's conditioned nictitating membrane response. Journal of Experimental Psychology: Animal Behavior Processes, 14, 320-333.

KenOE, E. J., \& HoLT, P. E. (1984). Transfer across CS-US intervals and sensory modalities in classical conditioning of the rabbit. Animal Learning \& Behavior, 12, 122-128.

Kehoe, E. J., Horne, A. J., Horne, P. S., \& Macrae, M. (1994). Summation and configuration between and within sensory modalities in classical conditioning of the rabbit. Animal Learning \& Behavior, 22 19-26.

Kehoe, E. J., Marshall-Goodell, B., \& Gormezano, I. (1987). Differential conditioning of the rabbit's nictitating membrane response to serial compound stimuli. Journal of Experimental Psychology: Animal Behavior Processes, 13, 17-30.

KeHOE, E. J., \& MORROW, L. D. (1984). Temporal dynamics of the rabbit's nictitating membrane response in serial compound conditioned stimuli. Journal of Experimental Psychology: Animal Behavior Processes, 10, 205-220.

KEHOE, E. J., \& NAPIER, R. M. (1991). In the blink of an eye: Real-time stimulus factors in delay and trace conditioning of the rabbit's nictitating membrane response. Quarterly Journal of Experimental Psychology, 43B, 257-277.

Kehoe, E. J., Schreurs, B. G., \& AMODEI, N. (1981). Blocking acquisition of the rabbit's nictitating membrane response to serial conditioned stimuli. Learning \& Motivation, 12, 92-108.

Kehoe, E. J., Schreurs, B. G., \& Graham, P. (1987). Temporal primacy overrides prior training in serial compound conditioning of the rabbit's nictitating membrane response. Animal Learning \& Behavior, 15, 455-464

KESNER, R. P. (1982). Mnemonic functions of the hippocampus: Correspondence between animals and humans. In C. P. Woody (Ed.), Conditioning: Representation of involved neural functions ( $\mathrm{pp}$. 75-88). New York: Plenum.

Kohler, E. A., \& Ayres, J. J. B. (1982). Blocking with serial and simultaneous compounds in a trace conditioning procedure. Animal Learning \& Behavior, 10, 277-287.

Kronforst-Collins, M. A., \& Disterfhoft, J. F. (1997). Lesions of the caudal area of the rabbit medial prefrontral cortex impair trace eyeblink conditioning. Society for Neuroscience Abstracts, 23, 782.

Mackintosh, N. J. (1975). A theory of attention: Variation in the associability of stimuli with reinforcement. Psychological Review, 82, 276-298.

Mackintosh, N. J. (1976). Overshadowing and stimulus intensity. Animal Learning \& Behavior, 4, 186-192.

Marshall-Goodell, B., Schreurs, B. G., \& Gormezano, I. (1982). Ruler vs. the Apple II/FIRST system analysis of analog signals in classical conditioning. Behavior Research Methods \& Instrumentation, 14, 519-525.

McClelland, J. L., Rumelhart, D. E., \& Hinton, G. E. (1986). The appeal of parallel distributed processing. In D. E. Rumelhart, J. L. McLelland, \& the PDP Research Group (Eds.), Parallel distributed processing: Explorations in the microstructures of cognition. Vol. 1. Foundations (pp. 3-44). Cambridge, MA: MIT Press.

MoORE, J. W., \& STICKNEY, K. J. (1980). Formation of attentionalassociative networks in real time: Role of the hippocampus and implications for conditioning. Physiological Psychology, 8, 207-217.

Moyer, J. R., Deyo, R. A., \& DisterhofT, J. F. (1990). Hippocampectomy disrupts trace eye-blink conditioning in rabbits. Behavioral Neuroscience, 104, 243-252.

Myers, C. E., \& Gluck, M. A. (1994). Context, conditioning and hippocampal re-representation. Behavioral Neuroscience, 108, 835-847. OrR, W. B., \& BERGER, T. W. (1985). Hippocampectomy disrupts the topography of conditioned nictitating membrane responses during re- 
versal learning. Journal of Comparative \& Physiological Psychology, 99, 35-45.

Pavlov, I. P. (1927). Conditioned reflexes: An investigation of the physiological activity of the cerebral cortex (G. V. Anrep, Trans.). London: Oxford University Press.

Pearce, J. M., \& Hall, G. (1980). A model for Pavlovian learning: Variations in the effectiveness of conditioned but not of unconditioned stimuli. Psychological Review, 87, 532-552.

Port, R. L., Mikhail, A. A., \& Patterson, M. M. (1985). Differential effects of hippocampectomy on classically conditioned rabbit nictitating membrane response related to interstimulus interval. Behavioral Neuroscience, 99, 200-208.

Port, R. L., Romano, A. G., Steinmetz, J. E., Mikhail, A. A., \& PatTERSON, M. M. (1986). Retention and acquisition of classical traceconditioned responses by rabbits with hippocampal lesions. Behavioral Neuroscience, 100, 745-752.

RaWLiNs, J. N. P. (1985). Associations across time: The hippocampus as a temporary memory store. Behavioral \& Brain Sciences, 8, 479-496.

Rescorla, R. A., \& WAGNer, A. R. (1972). A theory of Pavlovian conditioning: Variations in the effectiveness of reinforcement and nonreinforcement. In A. H. Black \& W. F. Prokasy (Eds.), Classical conditioning $I$ (pp. 64-99). New York: Appleton-Century-Crofts.

Ross, R. T., \& LoLoRDo, V. M. (1986). Blocking during serial featurepositive discriminations: Associative versus occasion-setting functions. Journal of Experimental Psychology: Animal Behavior Processes, 12, 315-324.

Ross, R. T., OrR, W. B., Holland, P. C., \& Berger, T. W. (1984). Hippocampectomy disrupts acquisition and retention of learned conditional responding. Behavioral Neuroscience, 98, 211 1-225.

RUDY, J. W., \& SuTHERLAND, R, J. (1989). The hippocampal formation is necessary for rats to learn and remember configural discriminations. Behavioural Brain Research, 34, 97-109.

RudY, J. W., \& SuTHERLAND, R. J. (1995). Configural association theory and the hippocampal formation: An appraisal and reconfiguration. Hippocampus, 5, 375-389.

Ryou, J. W., \& KIM, H. T. (1997). Lesion of the entorhinal cortex affects learning-related multiple unit activities in the hippocampus. Society for Neuroscience Abstracts, 23, 779.

SCANDRETT, J., \& GoRmEZANO, I. (1980). Microprocessor control and A/D data acquisition in classical conditioning. Behavior Research Methods \& Instrumentation, 12, 120-125.

SCAvio, M. J., \& GormEZANo, I. (1974). CS intensity effects upon rabbit nictitating membrane conditioning, extinction, and generalization. Pavlovian Journal of Biological Sciences, 9, 25-34.

Schmajuk, N. A., \& DiCarlo, J. J. (1992). Stimulus configuration, classical conditioning and hippocampal formation. Psychological Review, 99, 268-305.

Schmajuk, N. A., Lamoureux, J. A., \& Holland, P. C. (1998). Occasion setting: A neural network approach. Psychological Review, 105, 3-32.

Schmajuk, N. A., \& Moore, J. W. (1988). The hippocampus and the classically conditioned nictitating membrane response: A real-time attentional-associative model. Psychobiology, 16, 20-35.

Schmaltz, L. W., \& Theios, J. (1972). Acquisition and extinction of a classically conditioned response in hippocampectomized rabbits (Oryctolagus cuniculus). Journal of Comparative \& Physiological Psychology, 79, 328-333.

Schreurs, B. G., Kehoe, E. J., \& Gormezano, I. (1993). Concurrent associative transfer and competition in serial conditioning of the rabbit's nictitating membrane response. Learning \& Motivation, 24, 395-412.

SMITH, M. C. (1968). CS-US interval and US intensity in classical conditioning of the rabbit's nictitating membrane response. Journal of Comparative \& Physiological Psychology, 66, 679-687:

Solomon, P. R. (1977). Role of hippocampus in blocking and conditioned inhibition of the rabbit's nictitating membrane response. Journal of Comparative \& Physiological Psychology, 91, 407-417.

Solomon, P. R., Brennan, G., \& MoOre, J. W. (1974). Latent inhibition of the rabbit's nictitating membrane response as a function of CS intensity. Bulletin of the Psychonomic Society, 4, 445-448.

SOlOMON, P. R., \& MoOre, J. W. (1975). Latent inhibition and stimulus generalization of the classically conditioned nictitating membrane response in rabbits (Oryctolagus cuniculus) following dorsal hippocampal ablation. Journal of Comparative \& Physiological Psychology, 89, 1192-1203.

Solomon, P. R., Vander SchaAf, E. R., Weisz, D. J., \& Thompson, R. F. (1986). Hippocampus and trace conditioning of the rabbit's classically conditioned nictitating membrane response. Behavioral Neumscience, 100, 729-744.

SutherLand, N. S., \& Mackintosh, N. J. (1971). Mechanisms of animal discrimination learning. New York: Academic Press.

Sutherland, R. J., \& Rudy, J. W. (1989). Configural association theory: The role of the hippocampal formation in learning, memory, and amnesia. Psychobiology, 17, 129-144.

Sutton, R. S., \& BarTo, A. G. (1981). Toward a modern theory of adaptive networks: Expectation and prediction. Psychological Review, 88, 135-171.

Sutton, R. S., \& Barto, A. G. (1990). Time-derivative models of Pavlovian reinforcement. In M. Gabriel \& J. W. Moore (Eds.), Learning and computational neuroscience (pp. 497-537). Cambridge, MA: MIT Press.

THOMPSON, R. F., \& KRUPA, D. J. (1994). Organization of memory traces in the mammalian brain. Annual Review of Neuroscience, 17, 519-549.

Wagner, A. R., Logan, F. A., Haberlandt, K., \& Price, T. (1968). Stimulus selection in animal discrimination learning. Journal of Experimental Psychology, 76, 171-180.

WiCKENS, D. D. (1965). Compound conditioning in humans and cats. In W. F. Prokasy (Ed.), Classical conditioning (pp. 323-339). New York: Appleton-Century-Crofts.

(Manuscript received June 5, 1998; revision accepted for publication December 2, 1998.) 